\title{
Future Cell and Gene Therapy for Osteoarthritis (OA): Potential for Using Mammalian Protein Production Platforms, Irradiated and Transfected Protein Packaging Cell Lines for Over- Production of Therapeutic Proteins and Growth Factors
}

\author{
Ali Mobasheri
}

\begin{abstract}
In this paper I provide a personal perspective on future prospects for cell and gene therapy for osteoarthritis (OA) and how mammalian protein production platforms, virally transfected and irradiated protein packaging cell lines may be used as "cellular factories" for over-production of therapeutic proteins and growth factors, particularly in the context of intra-articular regenerative therapies. I will also speculate on future opportunities and challenges in this area of research and how
\end{abstract}

\footnotetext{
A. Mobasheri $(\bowtie)$

Department of Regenerative Medicine, State Research Institute Centre for Innovative Medicine, Vilnius, Lithuania

Research Unit of Medical Imaging, Physics and Technology, Faculty of Medicine, University of Oulu, Oulu, Finland

Centre for Sport, Exercise and Osteoarthritis Research Versus Arthritis, Queen's Medical Centre, Nottingham, UK

Sheik Salem Bin Mahfouz Scientific Chair for Treatment of Osteoarthritis with Stem Cells, King Abdulaziz University, Jeddah, Kingdom of Saudi Arabia e-mail: ali.mobasheri@imcentras.lt; ali.mobasheri@oulu.fi
}

new innovations in biotechnology will impact on the field of cell and gene therapy for OA, related osteoarticular disorders and the broader discipline of regenerative medicine for musculoskeletal disorders. Mammalian protein production platforms are likely to have a significant impact on synovial joint diseases that are amenable to cell and gene therapy using therapeutic proteins and growth factors. Future cell and gene therapy for OA will need to re-consider the current strategies that employ primary, aged and senescent cells with feeble regenerative properties and seriously consider the use of mammalian protein production platforms.

\section{Keywords}

Cell therapy · CHO - Gene therapy - GP-293 • Growth factors · HEK-293 · Mammalian protein production platforms · Osteoarthritis $(\mathrm{OA}) \cdot$ Transfected protein packaging cell lines - Transforming Growth Factor- $\beta$ $($ TGF- $\beta$ ) · Growth differentiation factor 5 (GDF5) · TissueGene-C (TG-C) 


\section{Abbreviations}

ADAMTS a disintegrin and metalloproteinase with thrombospondin motifs

BMI body mass index

BMP-7 bone morphogenic protein

CHO Chinese hamster ovary

DMOAD disease-modifying osteoarthritis drug

ECM extracellular matrix

EULAR European League Against Rheumatism

FDA Food and Drug Administration

FGF-18 fibroblast growth factor 18

GDF-5 growth differentiation factor 5

GM-CSF granulocyte macrophage-colony stimulating factor

GP-293 HEK 293-based retroviral packaging cell line

HEK-293 human embryonic kidney 293 cell line

IH intermittent hydrarthrosis

IL-1 $\beta \quad$ interleukin $1 \beta$

IL-6 interleukin 6

iNOS inducible nitric oxide synthase

JSW joint space width

MCB Master Cell Bank

MMP matrix metalloproteinase

MRI magnetic resonance imaging

MSC mesenchymal stem cell

NO nitric oxide

NSAIDs non-steroidal anti-inflammatory drugs

OA osteoarthritis

OARSI Osteoarthritis Research Society International

$\mathrm{PGE}_{2} \quad$ prostaglandin $\mathrm{E}_{2}$

PRP platelet rich plasma

R\&D research and development

RA rheumatoid arthritis

RMDs rheumatic and musculoskeletal diseases

ROS reactive oxygen species

SASP senescence-associated secretory phenotype

SV-40 simian virus 40
TG-C TissueGene-C

TGF- $\beta$ transforming growth factor $\beta$

TNF- $\alpha \quad$ tumour necrosis factor $\alpha$

\section{Introduction}

According to the European League Against Rheumatism (EULAR) there are more than 200 different forms of rheumatic and musculoskeletal diseases (RMDs). These diseases most commonly affect synovial joints. Osteoarthritis (OA) is the most common form of joint disorder with degenerative and inflammatory components (MartelPelletier et al. 2016). As a disease of aging, it is accountable for more disability in the elderly population than all other musculoskeletal diseases altogether across the developed and developing countries (Christensen et al. 2009). Recent information provided by the Osteoarthritis Research Society International (OARSI) suggests that OA is a serious disease, affecting 240 million people worldwide and is twice as likely to affect women than men over the age of 50. It is estimated that a "tsunami" of new OA cases will hit countries with a much larger ageing population in the developed world by the year 2050, when 130 million people will be suffering from OA worldwide and 40 million will be severely disabled.

Despite the growing prevalence and burden of OA there is no cure for this disease (Mobasheri 2013). In the absence of a cure, the only way to reduce the societal burden attributed to $\mathrm{OA}$ is to change gears and shift the approach to management, and focus on developing long-term strategies for prevention. The main treatments for OA include lifestyle measures, such as maintaining a healthy weight and exercising regularly, anti-inflammatory medication to reduce inflammation and relieve pain and supportive therapies to help make everyday activities easier. Surgery may be considered to repair, strengthen or replace components of damaged joints. However, when all other treatment options fail, joint arthroplasty is the final solution. 
OA is also a cause of significant morbidity. It limits daily life by reducing movement so that $25 \%$ of people affected cannot engage in normal daily routines and activities. It affects the professional and personal lives of the people affected and has adverse impacts on their partners, families, friends, careers and society as a whole. By reducing mobility OA significantly increases the risk of cardiovascular disease (Kim et al. 2016), diabetes (Louati et al. 2015) and hypertension (Courties et al. 2015; Calders and Van Ginckel 2017). ${ }^{1}$ OA contributes to depression and anxiety in many patients (Sharma et al. 2016) and is a major cause of sleep disturbance (Parmelee et al. 2015).

Signs and symptoms of OA include joint pain, stiffness, tenderness, loss of flexibility, crepitus and a grating sensation as the joint articulates. The affected joints hurt during or after movement. ${ }^{2}$ There may be inflammatory episodes and flares that lead to soft tissue inflammation around the joint and to joint effusion and swelling. The accumulation of excess fluid in the synovial space is known as intermittent hydrarthrosis (IH), although this is less common in OA compared to rheumatoid arthritis (RA). In later stages of the disease bone spurs known as osteophytes can form around the affected joint and these are seen on plain radiographs.

\section{The Hallmarks of Osteoarthritis}

All major diseases are characterised by "hallmarks", which summarise the key biological alterations that occur in that disease. For example, cancer comprises six biological capabilities that are gradually acquired during the multistep development of human tumors (Hanahan and Weinberg 2000; Hanahan and Weinberg 2011). In the case of OA, there are many similarities with the hallmarks of aging (López-Otín et al. 2013).

\footnotetext{
${ }^{1}$ https://www.arthritis.org/living-with-arthritis/ comorbidities/heart-disease/osteoarthritis-ups-cvd-risk. php

${ }^{2}$ https://www.mayoclinic.org/diseases-conditions/osteoar thritis/symptoms-causes/syc-20351925
}

The hallmarks of aging include genomic instability, telomere attrition, epigenetic alterations, loss of proteostasis, deregulated nutrient-sensing, mitochondrial dysfunction, cellular senescence, stem cell exhaustion, and altered intercellular communication. Many of the hallmarks of aging are also seen in OA. However, for the sake of simplicity, the gradual loss and degradation of articular cartilage is the major hallmarks of OA (Mobasheri and Batt 2016; Tonge et al. 2014). This feature is particularly important as is a clinical measure of disease progression when loss of articular cartilage is measured on plain radiographs over time as a reduction in joint space width (JSW). For decades we have used radiography as the "gold standard" to diagnose $\mathrm{OA}$ and assess disease progression over time in routine clinical practice and in clinical trials (Hunter et al. 2015). However, by the time the disease has been diagnosed using plain radiographs, it has already progressed significantly and there are suggestions that plain X-ray radiography should no longer be considered a surrogate outcome measure for longitudinal assessment of cartilage in clinical trials of new drugs and combination treatments for knee OA (Guermazi et al. 2011). However, cartilage thickness remains a key parameter that can determine the efficacy of new regenerative treatments and this will be discussed later in this article. In obese and overweight OA patients cartilage degrades even further and this is thought to occur through a combination of biomechanical mechanisms due to the excess weight and the pro-inflammatory cytokines (adipokines) and leptin produced by white adipose tissue (Francisco et al. 2018, 2019; Scotece and Mobasheri 2015).

\section{Molecular Alterations in OA}

The precise sequence of molecular events involved in the pathogenesis of $\mathrm{OA}$ are not clear. There is evidence that there are multiple phenotypes of OA with underlying molecular endotypes and these are likely to vary between individuals (van Spil et al. 2019; Mobasheri et al. 2019). Therefore, OA is no longer regarded as a 
homogeneous disease. It is a heterogeneous disease that can be stratified into different subsets and subgroups (Driban et al. 2010), some of which may overlap in older patients with multiple co-morbidities, although all the different pathways lead to cartilage erosion and loss of joint function. In terms of disease initiation, it is thought that there is a long and asymptomatic "molecular phase", which is followed many years later by radiographic changes and the appearance of symptoms (Kraus et al. 2015). In addition to aging, obesity, gender and genetics, inciting risk factors may include previous joint trauma or repetitive injuries or the presence of metabolic and endocrine disease (Fig. 1).

There are biomechanical (Englund 2010), inflammatory (Berenbaum 2013) and metabolic (Mobasheri et al. 2017) factors that have been shown to play key roles in the initiation and progression of the disease. We now know that chondrocytes are not simply passive participants and bystanders in disease progression. Chondrocytes become progressively inflammatory and activated in OA. The increased pro-catabolic and pro-inflammatory factors in OA reduce anabolic activity, alter cellular metabolism, and disturb the delicate balance between extracellular matrix (ECM) synthesis and degradation (Loeser 2011). Other joint tissues can contribute to the loss of homeostasis and metabolic regulation in the joint as well, since $\mathrm{OA}$ also involves the synovial membrane (Siebuhr et al.
2016; Rahmati et al. 2016), subchondral bone (Mahjoub et al. 2012) and peri-articular soft tissues (Goldring and Goldring 2007). Figure 2 summarises the major molecular players involved in the alterations that occur in the OA joint.

Synovitis appears to be a very common feature in both the early and late phases of OA (Scanzello and Goldring 2012), with infiltrating macrophages, $\mathrm{T}$ cells and mast cells (de LangeBrokaar et al. 2012). Synovitis and the innate inflammatory network (Liu-Bryan 2013) expectedly play a key role in OA; pro-inflammatory cytokines are most frequently found in the inflamed synovium (de LangeBrokaar et al. 2012). Catabolic and pro-inflammatory mediators such as cytokines, reactive oxygen species (ROS), nitric oxide (NO), prostaglandin $\mathrm{E}_{2} \quad\left(\mathrm{PGE}_{2}\right)$ and neuropeptides from the inflamed synovium, all affect chondrocyte metabolism and matrix turnover in the cartilage (Sutton et al. 2009). Synovitis leads to excess production of proteolytic enzymes responsible for cartilage breakdown (Sellam and Berenbaum 2010). On its turn, cartilage matrix catabolism releases molecules that perpetuate synovial inflammation, creating a vicious and self-perpetuating cycle (Sellam and Berenbaum 2010). Inflammatory mediators from chondrocytes and synoviocytes also drive oxidative stress and inflict joint damage by releasing ROS (Poulet and Beier 2016). Once activated by stress such as pro-inflammatory cytokines,
Fig. 1 Risk factors for osteoarthritis (OA)

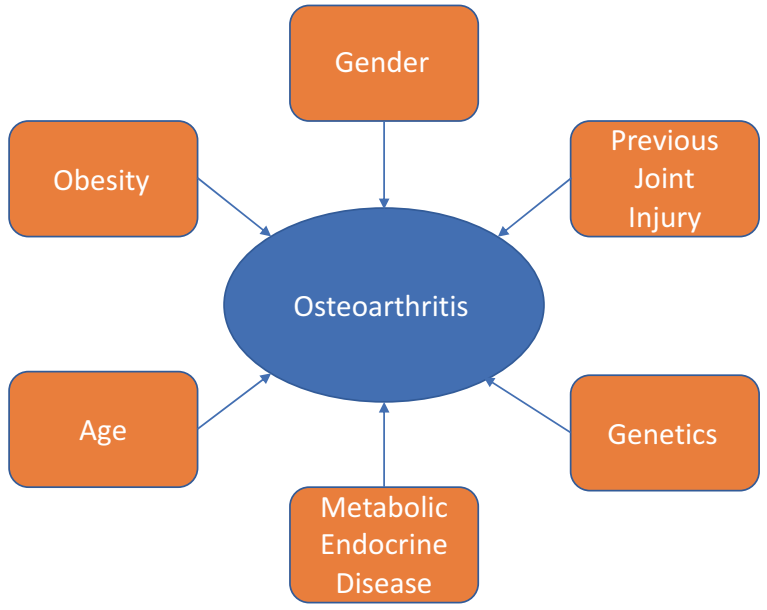




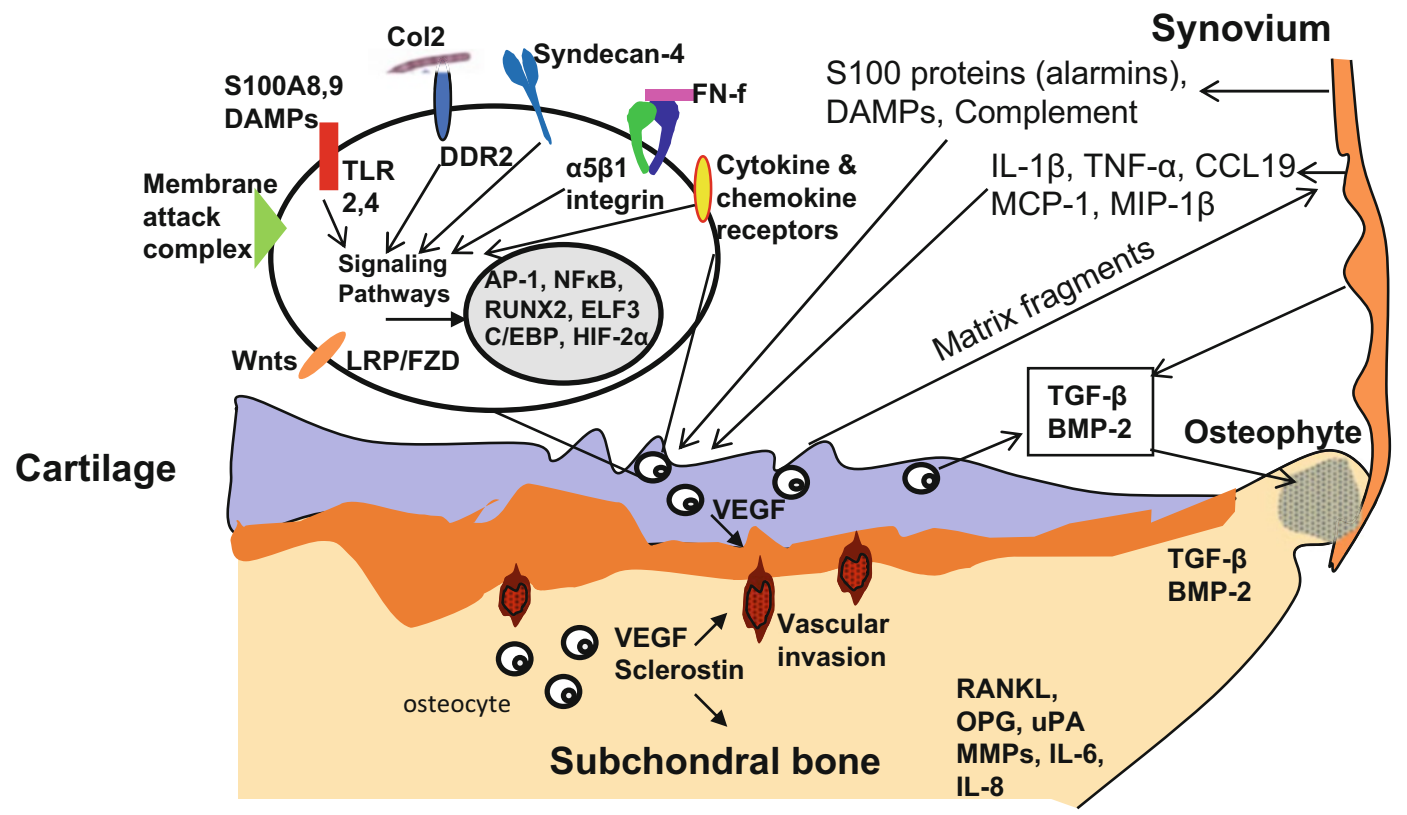

Fig. 2 Chondral, subchondral and synovial alterations in OA. Reproduced with permission from Mobasheri et al., (Chapter 3 - Cartilage and Chondrocytes, Kelley \& Firestein's Textbook of Rheumatology 11th Edition, in press)

prostaglandins and ROS, the normally quiescent articular chondrocytes become activated and undergo a phenotypic shift through a phenomenon recently described as "chondrosenescence" and the development of a senescence-associated secretory phenotype (SASP) (Salminen et al. 2012) leading to further disruption of homeostasis and metabolism in cartilage (Mobasheri et al. 2015).

As mentioned earlier, at the present time, there is no cure for OA. The existing treatments are unsatisfactory, and only address the symptoms (Zhang et al. 2016). ${ }^{3}$ There are no approved drugs that prevent OA and there are no approved drugs that impede the progression of the disease. ${ }^{4}$ In many cases of advanced OA joint surgery and replacement is the only viable solution when joint function has been irreversibly and permanently compromised (Katz et al. 2010). Arthroplasty can replace the knee or the hip, but it cannot

\footnotetext{
${ }^{3}$ https://www.arthritisresearchuk.org/arthritis-informa tion/arthritis-today-magazine/156-spring-2012/osteoarthri tis.aspx

${ }^{4}$ https://www.bones.nih.gov/health-info/bone/osteoporo sis/conditions-behaviors/osteoporosis-arthritis
}

restore the original function of the joint (Crawford and Murray 1997). OARSI treatment guidelines propose that all OA patients should receive up-to-date information and education to enable them to self-manage their disease to some extent (Zhang et al. 2008). All OA patients are advised to manage their weight and lose weight if they have a high body mass index (BMI), remain active and exercise regularly (Bliddal et al. 2014). All OA patients are advised to avoid a sedentary lifestyle because joints need to move and articulate. Clinical evidence suggests that some OA patients will benefit from drugs, but the currently existing drugs (non-steroidal anti-inflammatory drugs, NSAIDs) only address the symptoms of pain and inflammation, and they do this unsatisfactorily, with small effect sizes and significant side effects and cardiovascular, gastrointestinal, renal and hepatobiliary risks (Matthews and Hunter 2011). Many OA patients remain dissatisfied with the currently approved pharmacological interventions. ${ }^{5}$

\footnotetext{
${ }^{5}$ https://www.ncbi.nlm.nih.gov/books/NBK333051/
} 
There is emerging evidence that some OA patients benefit from joint injections, including intra-articular steroids and viscosupplementation. However, numerous and repeated steroid injections are not recommended. Furthermore, viscosupplementation does not work well for every patient especially in advanced cases, where significant joint degradation has already occurred and there is bone-on-bone contact upon weightbearing and joint mobilization (MartelPelletier et al. 2016). Many pharmaceutical companies that were active in the area of OA drug development in the 1990's exited this challenging disease area in the 2000's because they had exclusively focused on developing oral drugs for inhibiting matrix degrading enzymes, but these targets were too downstream and failed to inhibit key upstream catabolic pathways and disease driving switches. The reduced Research and Development (R\&D) efficiency of pharmaceutical companies has made it necessary for them to realign their $R \& D$ concepts and strategies (Schuhmacher et al. 2016). The outcomes of the clinical trials of matrix metalloproteases and cathepsins were poor, because of adverse events and fibrotic events. The pharmaceutical companies involved learned a very important lesson: targeting end-stage catabolic mediators is unlikely to work as a strategy for curing OA.

So why is disease modification in OA so challenging? Why are existing treatments so futile? Why has progress in OA drug development been so slow compared to other arthritic and rheumatic diseases? The answers to these questions are not so straightforward. The problem is that patients desire effective pain relief but the drug companies are more ambitious, hoping for treatments that address symptoms as well as improving structure. Unfortunately, there are no such magic bullets in the modern drug development arena. We know that the development of symptom modifying OA drug is now exploding with a plethora of pain pathways being pursued and multiple candidates are in advanced stages of clinical development. However, structure modification in OA remains extremely complex with significant development challenges (Hellio Le Graverand-Gastineau
2009). To make progress, we do need to revisit some basic concepts in physiology and pathophysiology. We know that the balance between anabolic and catabolic activity is disturbed in OA and normal physiological turnover of joint tissues in perturbed (Fig. 3). New drugs must address the imbalance between catabolic and anabolic activity in order to halt disease progression. New treatments must have the capacity to positively influence cartilage metabolism.

The pharma companies that are still engaged in this challenging arena have learned important and useful lessons from the failures of previously defeated players. Drug companies that remain engaged with the OA challenge have accepted that targeting inflammation and catabolic activity is not enough. Greater efforts must be made to stimulate anabolic activity and this is one of the main reasons why current therapeutic strategies are focusing on the development of cell and gene therapy and recombinant anabolic growth factors. There is significant ongoing effort in this area, especially focusing on the improvement of autologous chondrocyte transplantation techniques, the use of stem cells and the application of chondrocyte and stem cell-derived growth factors in preclinical and translational models of OA. For example, emerging regenerative therapies that target OA joint tissues include injectable biological such as mesenchymal stem cells (MSCs) (Mobasheri et al. 2009, 2014; Richardson et al. 2016), platelet rich plasma (PRP), growth differentiation factor 5 (GDF5) (Enochson et al. 2014), bone morphogenic protein 7 (BMP-7) (Chubinskaya et al. 2007; FunckBrentano et al. 2014), fibroblast growth factor 18 (FGF-18) (Gigout et al. 2017; Yu and Hunter 2016; Lohmander et al. 2014) or injectable small molecules and drugs such as WNT signalling pathway inhibitors (Lories et al. 2013; Stampella et al. 2018) or even revisiting the classical approaches to inhibiting extracellular matrix degradation - by targeting catabolic enzymes using matrix metalloproteinase (MMP) inhibitors and a disintegrin and metalloproteinase with thrombospondin motifs (ADAMTS) inhibitors (Yang et al. 2017; Murphy 2017) (Fig. 4). 
Fig. 3 (a)

Loss of the

delicate

physiological balance

between anabolism and

catabolism in OA leads to

impaired cartilage

metabolism and disease

progression. (b) Effective

drugs can bring cartilage

metabolism back into

equilibrium and stop

disease progression
A

Cartilage

Metabolism

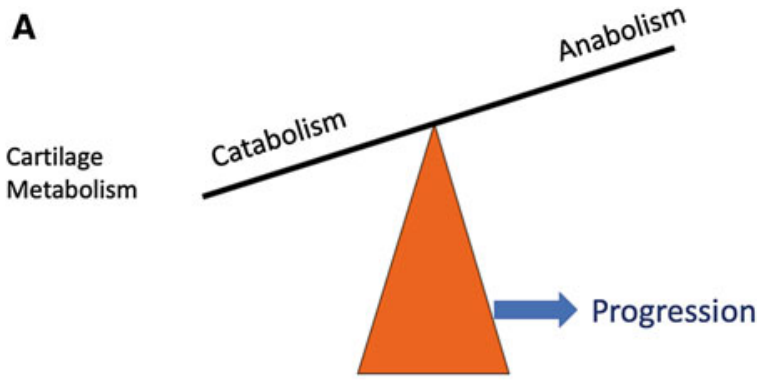

B

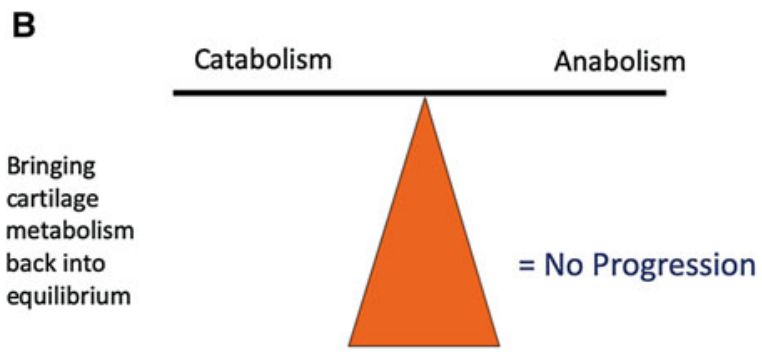

Agents for regulating cartilage catabolism and anabolism

- MMP inhibitors

- ADAMTS inhibitors

- Growth factors

- Mesenchymal stem cells (MSCs)

- Platelet rich plasma (PRP)

- Cathepsin inhibitors

- Wnt signaling inhibitors

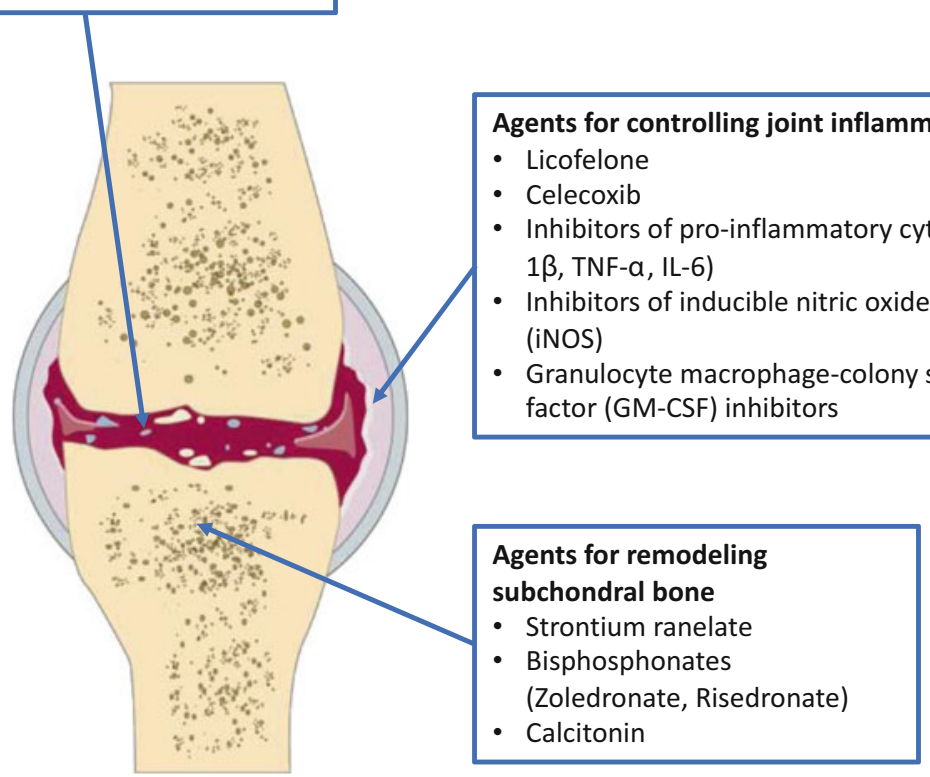

Fig. 4 Therapeutic strategies for targeting synovial joint structure in OA. (Reproduced with permission from Huang et al. 2017) 
One crucial quantum leap in the development of new therapies for OA has been the realisation and acceptance that the most ideal treatments must target the affected joint through injection rather than the oral route. Another important advance has come from the field of rheumatology and the treatment of RA: multiple joint injections may be needed and a single joint injection is unlikely to work, even if we have a magic bullet. However, many of the key researchers in this field are still stuck in silos and have yet to accept that biological therapy, whether using autologous chondrocytes and stem cells cannot be achieved with primary tissue-derived native cells. Despite progress and advancements in MSC biology and the introduction of various bioactive scaffolds and growth factors in preclinical studies, current clinical trials are still at very early stages with preliminary aims to evaluate safety, feasibility and efficacy (Lee and Wang 2017) and this is where we must focus our efforts. Clinical trials of stem cell therapies and MSCs in particular have yet to demonstrate efficacy and while we anxiously wait for outcomes of several ongoing stem cell trials in $\mathrm{OA}$, there are a number of companies that have innovated by focusing efforts on developing treatments using mammalian protein production platforms, including transformed and modified cells, as well as immortalized cells that were originally developed as research tools and protein packaging cell lines for over-production of target proteins. It is evident that the field of biotechnology has already offered us powerful and versatile tools for the over-production of therapeutic proteins but since many OA researchers are still stuck in silos and rarely speak to scientists in other fast-moving disciplines, such as biotechnology, we are unaware of the expanded and enhanced toolbox that is at our disposal. We need to break down these disciplinary barriers, open-up our minds and accept that new therapeutic innovations in OA are likely to come from other biological and biomedical disciplines, including biotechnology, protein engineering and immunology.

\section{4 \\ Mammalian Protein Production Platforms}

Mammalian protein production platforms are indispensable cell factories that are used for large-scale production of antibodies and therapeutic proteins (Zucchelli et al. 2016). Expression of antibodies and proteins in mammalian cells is a key technology that is vitally important for many functional studies on human and higher eukaryotic genes. Mammalian cell expression systems allow the production of proteins, especially of those of clinical relevance and human origin (Aricescu and Owens 2013). Over the last few decades these platforms have evolved and had a profound impact in many areas of basic and applied research, and an increasing number of biological drugs are now recombinant mammalian proteins made using these tools (Bandaranayake and Almo 2014). Recombinant proteins and a vast array of antibodies are now produced in mammalian cell lines instead of bacterial expression systems to ensure that proper protein folding and posttranslational modifications, which are essential for full biological activity, are properly introduced in a eukaryotic and "mammalian" context. Mammalian cell expression systems are the dominant tools for producing complex biotherapeutic proteins (Estes and Melville 2014). The most commonly used mammalian cell lines found in the research and industrial therapeutic protein production settings are Chinese hamster ovary cells (CHO) (Omasa et al. 2010) and human embryonic kidney 293 cells (HEK-293) (Dyson 2016).

Various mammalian and non-mammalian expression systems are also being used for protein and glycoprotein production and recent cellular engineering strategies have been developed to increase protein and glycoprotein productivity (Lalonde and Durocher 2017). "Omics" technologies are continually being used to improve cellular expression systems and enhance such platforms for therapeutic protein production. Figure 5 summarises the expression systems used for protein and glycoprotein production by industry. 
Fig. 5 Expression systems used for protein and glycoprotein production by biopharmaceutical industries. (Adapted from Lalonde and Durocher 2017)

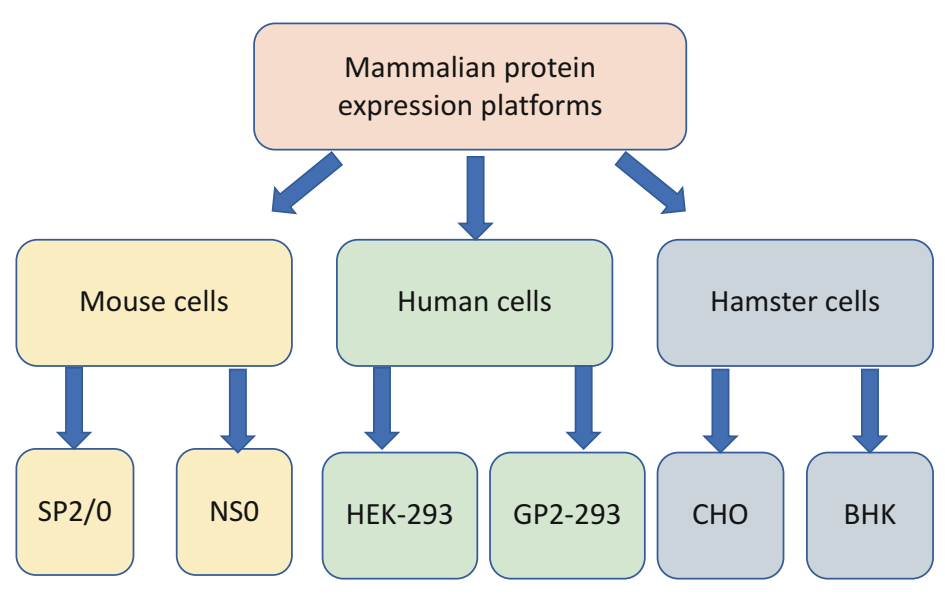

Transient expression systems in mammalian cells have also become the method of choice for producing large quantities of antibodies (Vink et al. 2014). By using a combination of simian virus 40 (SV40) large T antigen, p21 and p27, it has been possible to scale-up expression level of antibodies, from $0.1 \mathrm{ml}$ up to $1200 \mathrm{ml}$ in bioreactors (Vink et al. 2014). The ability to scale-up allows biotechnology companies to produce sufficient quantities of therapeutic antibodies and proteins for tests in preclinical studies and early phase clinical trials.

\section{$5 \quad$ Platforms for Over Production of Recombinant Growth Factors}

If a pharmaceutical company or a biotechnology company aims to make large quantities of a growth factor capable of stimulating cartilage matrix synthesis, it might be useful to have access to mammalian cell models that truly mimic chondrocytes, with phenotypic chondrocytic properties. There are several chondrocyte-like transformed cell-lines developed by Dr. Mary Goldring. However, none of these cells have been used in such a context. At present, there are no cell-lines derived from cartilage or other joint tissues that are truly comparable to $\mathrm{CHO}$ or
HEK-293 cells. Therefore, other cellular models must be employed, including CHO, HEK-293 cells and their derivatives such as GP2-293. These are immortalized cell lines that function as "cellular factories" for over-production of proteins. GP2-293 cells are specialised protein packaging cells. These cells are specialised transfection models, protein packaging tools and "cellular factories" for over-production of target human proteins and are promising candidates for over-producing therapeutic proteins and growth factors that native primary cells (i.e. chondrocytes) or stem cells (i.e. MSCs) cannot produce in sufficiently large quantities, either in the short-term or in the long-term. Although these cells cannot be used in their immortalized form for the development of clinically relevant cell therapies for OA, they can be irradiated to obliterate their proliferation capacity so that they remain protein packaging cellular factories, but without the ability to proliferate. Elimination of their proliferation through irradiation makes the use of such cells feasible in cellular therapies for $\mathrm{OA}$, especially if the cells are to be injected into the closed micro-environment of the synovial joint, isolated from the circulatory system. Irradiated cells will retain their capacity for protein over-production, but they cannot divide and proliferate, which means that they will die shortly after being injected into the joint. 
6

Case Study: Production
of Transforming Growth
Factor $\beta 1$ (TGF- $\beta 1$ ) by GP2-293
in the Kolon TissueGene
Cell and Gene Therapy
Product TG-C

In November 2018 Kolon TissueGene, Inc. based in Rockville, MD, announced that it has treated its first patient in the pivotal Phase III clinical trials of TG-C (the product is known as TG-C in the United States of America and as Invossa in South Korea), a revolutionary cell and gene therapy for the treatment of knee OA. TG-C is a unique first-in-class cell and gene therapy targeting knee OA through a single intra-articular injection of joint-derived chondrocytes, irradiated GP2-293 cells and, most importantly, the biological growth factors that they overproduce to possibly promote anabolic repair and regeneration in the diseased joint" as a future possibility in the treatment for OA (Fig. 6).

The first dosing in November 2018 followed the lifting of a clinical hold by the United States Food and Drug Administration (FDA) in July 2018. The phase III trials for US approval of TG-C were expected to recruit over a thousand patients in approximately 60 clinical sites across the United States. This ambitious trial was hoping to assess pain and physical function endpoints as well as imaging outcomes, including magnetic resonance imaging (MRI), radiographs and wet biochemical markers in patients receiving TG-C treatment.

Clinical trials of this approach have demonstrated some degree of pain relief, increased mobility, as well as indicators of reduced OA progression and improvements in joint structure, function and reduced stiffness. The allogeneic (off-the-shelf) drug consisting of cells and biological growth factors could potentially provide an alternative to traditional pharmacological OA treatments, which are largely unsatisfactory, with numerous undesired side-effects.

The ultimate aim is to achieve symptom and structure modification to the extent that the knee joint is preserved and surgery is delayed, for a substantial period of time. Knee arthroplasty is not for everyone, and is risky for some patients and costly for healthcare providers.

Thus far, with the exception of weight loss and exercise for overweight and obese individuals with OA, there are no effective therapies that can halt or delay the progression of $\mathrm{OA}$ and minimize the need for multiple surgical interventions.

\section{DMOAD Status for TG-C}

A Phase II clinical trial conducted by Kolon TissueGene in the United States demonstrated a

\section{General Concept for TG-C Invossa}

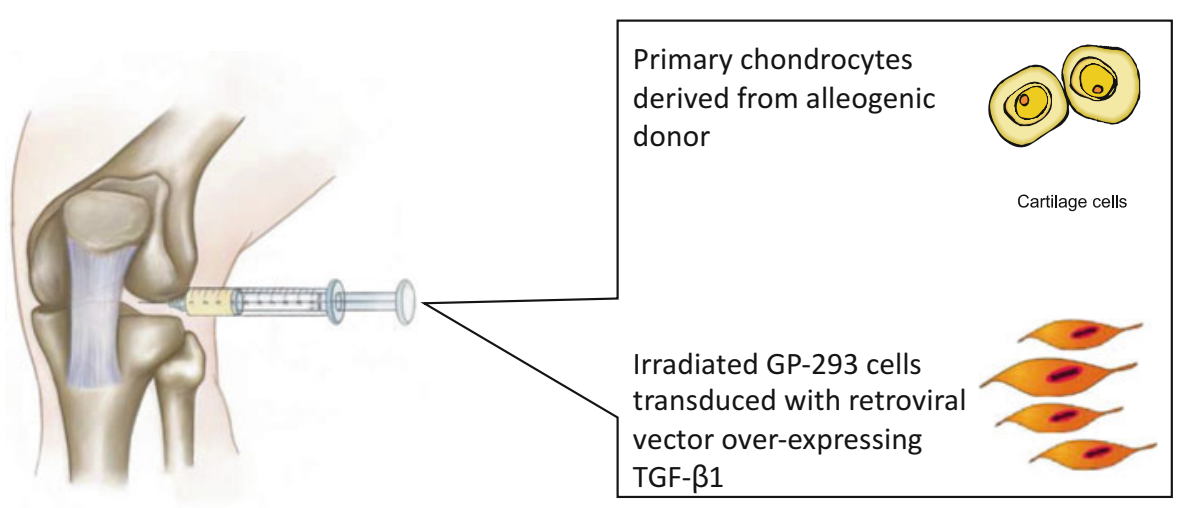

Fig. 6 The intra-articular injection concept for TG-C Invossa, a novel cell and gene therapy targeting knee OA through a single intra-articular injection of joint-derived primary chondrocytes, irradiated GP2-293 that produce TGF- $\beta 1$, the biological growth factor that promotes anabolic repair and regeneration 
two-year improvement of pain and function. The company then sought to continue supporting these efforts through its recently initiated national Phase III clinical trial across the United States. In addition, Kolon TissueGene has designed a trial to seek a disease-modifying osteoarthritis drug (DMOAD) designation for TG-C from the FDA, potentially making TG-C the first cell and gene therapy to receive such an elevated DMOAD status.

\section{Use of GP2-293 Cells in TG-C}

The human GP2-293 cell line is one of the key components of TG-C. These cells carry out the vital function of over-producing the crucially important growth factor TGF- $\beta 1$. The GP2-293 cells have been used throughout the whole developmental process from the first production of the Master Cell Bank (MCB) to the next step, which is the development of the working cell bank and the final product formulation. As mentioned earlier, GP2-293 is a HEK 293-based retroviral packaging cell line used for large-scale protein production. It is a cellular platform for overproduction of therapeutically relevant human proteins. This is the first time that such a human protein production platform has been employed in the context of OA treatment and cartilage regeneration. They are transformed with adenovirus type $5 \mathrm{DNA}$ and the cells were engineered to express the MoMuLV Gag and Pol proteins. Effectively these cells are a protein producing tool and "cellular factory". Native patient derived chondrocytes simply do not have the capacity to over-produce TGF- $\beta 1$ in sufficiently high quantities for cellular therapy and regenerative applications.

\section{Safety of GP2-293 Cells in TG-C}

Transduced and irradiated GP2-293 cells may be transformed cells but since they have lost their capacity for proliferation, they cannot proliferate. Therefore, the GP2-293 cells in TG-C cannot survive and proliferate in the joint. These cells will simply carry out their transient function as radiation inactivated transfection models, protein packaging tools and "cellular factories" for overproduction of therapeutic TGF- $\beta 1$. Therefore, the cells cannot survive for more than a very short period after being injected into the joint. The Korean Food and Drug Administration and the Ministry of Health in South Korea have stated they are not concerned about the safety of Invossa, the Korean version of TG-C, noting that cells no longer survive 44 days after administration. Furthermore, no drug-related side effects were identified from those subject to clinical trials. ${ }^{6}$ After the cells carry out their TGF- $\beta 1$ over-production duties, they will die and their remains will be cleared by joint resident inflammatory macrophages through the process of phagocytosis (Fig. 7).

The scientific basis for the use of mammalian cell transfection models is clear in the development of TG-C. There is a well-established literature on the use of HEK-293 cells as a transfection model and cell culture model for protein production. The efficacy and safety of HEK-293 cells and their derivatives in regenerative medicine has not been extensively reviewed but the prospects for future use of transfection tools in regenerative medicine and cell therapy is very positive, especially since native and untransformed cells do not have the appropriate regenerative capacity.

\section{Summary and Conclusions}

Cell and gene therapy for OA is a thriving and promising area of research and clinical development. This is a technologically challenging area but thanks to the innovations coming from the field of biotechnology and advances in mammalian protein production platforms, transfected and irradiated protein packaging cell systems new therapeutics can be developed and tested for OA. These mammalian platforms may be used as "cellular factories" for over-production of

\footnotetext{
${ }^{6} \mathrm{http} / / / \mathrm{www} \cdot$ businesskorea.co.kr/news/articleView.html? idxno $=32318$
} 
Fig. 7 Phagocytosis and destruction of dead GP2-293 or their cellular debris by joint resident macrophages

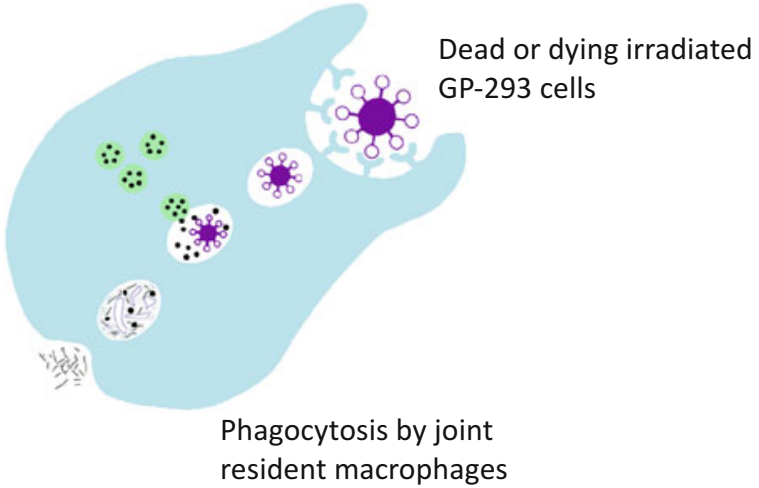

therapeutic proteins and growth factors, especially for intra-articular regenerative therapies. I would speculate that in the near future we will see many new innovations in this area, as we have seen for other disease areas using similar biotechnology tools.

The painful fact is that native and primary cells are unlikely to have the capacity for producing sufficient quantities of growth factors for stimulating cartilage repair. Mammalian cells such as HEK-293 and their derivative GP2-293 counterparts have the capacity to transiently produce high quantities of many therapeutic growth factors in addition to TGF- $\beta 1$. If these cells are irradiated, such as the GP2-293 in the TG-C product, they will gradually die off in the joint within a few days of performing their protein over-production duties. So what happens to these cells after they have died? The dead cells and their debris will be cleared and destroyed by joint macrophages.

I speculate that all future cellular and gene therapy will require packaging cell lines and the field of cell and gene therapy for OA will benefit from a reality check regarding the poor regenerative capacity of native and patient derived cells, which are unlikely to work without a helping hand from protein packaging mammalian cells. Hopefully some of the future packaging cell tools will be derived from chondrocytes and bone for application in cartilage and bone regeneration. However, in the meantime, we must continue to use and refine existing cellular models while we develop new cartilage-derived protein packaging cells. Innovations in biotechnology will further propel new therapeutic concepts and impact positively on the field of cell and gene therapy for OA, related osteoarticular disorders and the broader discipline of regenerative medicine for musculoskeletal disorders. Mammalian protein production platforms are likely to have a significant and positive impact on synovial joint diseases that are amenable to cell and gene therapy using therapeutic proteins and growth factors.

Acknowledgements The author wishes to thank Dr. Mary Goldring at the Hospital for Special Surgery in New York for permission to use Fig. 2 from the "Cartilage and Chondrocytes" chapter in Kelley \& Firestein's Textbook of Rheumatology 11th Edition, (in press). Miss Soraya Mobasheri provided the original digital artwork in Fig. 4 and to Miss Roxana Mobasheri supplied the original digital artwork in Figs. 6 and 7.

Financial Support and Sponsorship The author has received funding from the following sources: The European Commission Framework 7 programme (EU FP7; HEALTH.2012.2.4.5-2, project number 305815; Novel Diagnostics and Biomarkers for Early Identification of Chronic Inflammatory Joint Diseases). The Innovative Medicines Initiative Joint Undertaking under grant agreement No. 115770, resources of which are composed of financial contribution from the European Union's Seventh Framework programme (FP7/2007-2013) and EFPIA companies' in-kind contribution. The author also wishes to acknowledge funding from the European Commission through a Marie Curie Intra-European Fellowship for Career Development grant (project number 625746; acronym: CHONDRION; FP7-PEOPLE-2013-IEF). The author also wishes to acknowledge financial support from the European Structural and Social Funds (ES Struktūrinès Paramos) through the Research Council of Lithuania (Lietuvos Mokslo 
Taryba) according to the activity 'Improvement of researchers' qualification by implementing World-Class R\&D projects' of Measure No. 09.3.3-LMT-K-712 (grant application code: 09.3.3-LMT-K-712-01-0157, agreement No. DOTSUT-215) and further financial support from the European Structural and Social Funds through the Research Council of Lithuania (Lietuvos Mokslo Taryba) according to the Programme "Attracting Foreign Researchers for Research Implementation", Grant No 0.2.2-LMTK-718-02-0022.

The funders had no role in the conception and drafting of this review paper, in the collection, analysis, or interpretation of data; in the writing of the manuscript, or in the decision to publish. The author has received payments from King Abdulaziz University, Jeddah, Kingdom of Saudi Arabia. The author also declares that he has consulted for the following companies in the last 3 years: Abbvie, Aché Laboratórios Farmacêuticos S.A., AlphaSights, Galapagos NV, Guidepoint Global, Kolon TissueGene, Pfizer Consumer Health $(\mathrm{PCH})$, Servier, Bioiberica S.A. and Science Branding Communications.

Conflicts of Interest The author declares no competing interests.

\section{Bibliography}

Aricescu AR, Owens RJ (2013) Expression of recombinant glycoproteins in mammalian cells: towards an integrative approach to structural biology. Curr Opin Struct Biol 23(3):345-356

Bandaranayake AD, Almo SC (2014) Recent advances in mammalian protein production. FEBS Lett 588 (2):253-260

Berenbaum F (2013) Osteoarthritis as an inflammatory disease (osteoarthritis is not osteoarthrosis!). Osteoarthr Cartil 21(1):16-21

Bliddal H, Leeds AR, Christensen R (2014) Osteoarthritis, obesity and weight loss: evidence, hypotheses and horizons - a scoping review. Obes Rev 15(7):578-586

Calders P, Van Ginckel A (2017) Presence of comorbidities and prognosis of clinical symptoms in knee and/or hip osteoarthritis: a systematic review and meta-analysis. Semin Arthritis Rheum 47(6):805-813

Christensen K, Doblhammer G, Rau R, Vaupel JW (2009) Ageing populations: the challenges ahead. Lancet 374 (9696):1196-1208

Chubinskaya S, Hurtig M, Rueger DC (2007) OP-1/BMP7 in cartilage repair. Int Orthop 31(6):773-781

Courties A, Gualillo O, Berenbaum F, Sellam J (2015) Metabolic stress-induced joint inflammation and osteoarthritis. Osteoarthr Cartil 23(11):1955-1965

Crawford RW, Murray DW (1997) Total hip replacement: indications for surgery and risk factors for failure. Ann Rheum Dis 56(8):455-457 de Lange-Brokaar BJE, Ioan-Facsinay A, van Osch GJVM et al (2012) Synovial inflammation, immune cells and their cytokines in osteoarthritis: a review. Osteoarthr Cartil 20(12):1484-1499

Driban JB, Sitler MR, Barbe MF, Balasubramanian E (2010) Is osteoarthritis a heterogeneous disease that can be stratified into subsets? Clin Rheumatol 29 (2):123-131

Dyson MR (2016) Fundamentals of expression in mammalian cells. Adv Exp Med Biol 896:217-224

Englund M (2010) The role of biomechanics in the initiation and progression of OA of the knee. Best Pract Res Clin Rheumatol 24(1):39-46

Enochson L, Stenberg J, Brittberg M, Lindahl A (2014) GDF5 reduces MMP13 expression in human chondrocytes via DKK1 mediated canonical Wnt signaling inhibition. Osteoarthr Cartil 22(4):566-577

Estes S, Melville M (2014) Mammalian cell line developments in speed and efficiency. Adv Biochem Eng Biotechnol 139:11-33

Francisco V, Pino J, Gonzalez-Gay MA et al (2018) Adipokines and inflammation: is it a question of weight? Br J Pharmacol 175(10):1569-1579

Francisco V, Ruiz-Fernández C, Pino J et al (2019) Adipokines: linking metabolic syndrome, the immune system, and arthritic diseases. Biochem Pharmacol 165:196-206

Funck-Brentano T, Bouaziz W, Marty C, Geoffroy V, Hay E, Cohen-Solal M (2014) Dkk-1-mediated inhibition of Wnt signaling in bone ameliorates osteoarthritis in mice. Arthritis Rheum (Hoboken, NJ) 66 (11):3028-3039

Gigout A, Guehring H, Froemel D et al (2017) Sprifermin (rhFGF18) enables proliferation of chondrocytes producing a hyaline cartilage matrix. Osteoarthr Cartil 25 (11):1858-1867

Goldring MB, Goldring SR (2007) Osteoarthritis. J Cell Physiol 213(3):626-634

Guermazi A, Roemer FW, Burstein D, Hayashi D (2011) Why radiography should no longer be considered a surrogate outcome measure for longitudinal assessment of cartilage in knee osteoarthritis. Arthritis Res Ther 13(6):247

Hanahan D, Weinberg RA (2000) The hallmarks of cancer. Cell 100(1):57-70

Hanahan D, Weinberg RA (2011) Hallmarks of cancer: the next generation. Cell 144(5):646-674

Hellio Le Graverand-Gastineau MP (2009) OA clinical trials: current targets and trials for OA. Choosing molecular targets: what have we learned and where we are headed? Osteoarthr Cartil 17(11):1393-1401

Huang Z, Ding C, Li T, Yu SP-C (2017) Current status and future prospects for disease modification in osteoarthritis. Rheumatology (Oxford) 57:1-16

Hunter DJ, Altman RD, Cicuttini F et al (2015) OARSI clinical trials recommendations: knee imaging in clinical trials in osteoarthritis. Osteoarthr Cartil 23(5):698-715 
Katz JN, Earp BE, Gomoll AH (2010) Surgical management of osteoarthritis. Arthritis Care Res 62 (9):1220-1228

Kim HS, Shin J-S, Lee J et al (2016) Association between knee osteoarthritis, cardiovascular risk factors, and the Framingham risk score in South Koreans: a crosssectional study. PLoS One 11(10):e0165325

Kraus VB, Blanco FJ, Englund M, Karsdal MA, Lohmander LS (2015) Call for standardized definitions of osteoarthritis and risk stratification for clinical trials and clinical use. Osteoarthr Cartil 23(8):1233-1241

Lalonde M-E, Durocher Y (2017) Therapeutic glycoprotein production in mammalian cells. J Biotechnol 251:128-140

Lee WY, Wang B (2017) Cartilage repair by mesenchymal stem cells: clinical trial update and perspectives. J Orthop Translat 9:76-88

Liu-Bryan R (2013) Synovium and the innate inflammatory network in osteoarthritis progression. Curr Rheumatol Rep 15(5):323

Loeser RF (2011) Aging and osteoarthritis. Curr Opin Rheumatol 23(5):492-496

Lohmander LS, Hellot S, Dreher D et al (2014) Intraarticular sprifermin (recombinant human fibroblast growth factor 18) in knee osteoarthritis: randomized, double-blind, placebo-controlled trial. Arthritis Rheumatol (Hoboken, NJ) 66(7):1820-1831

López-Otín C, Blasco MA, Partridge L, Serrano M, Kroemer G (2013) The hallmarks of aging. Cell 153 (6):1194-1217

Lories RJ, Corr M, Lane NE (2013) To Wnt or not to Wnt: the bone and joint health dilemma. Nat Rev Rheumatol 9(6):328-339

Louati K, Vidal C, Berenbaum F, Sellam J (2015) Association between diabetes mellitus and osteoarthritis: systematic literature review and meta-analysis. RMD Open 1(1):e000077

Mahjoub M, Berenbaum F, Houard X (2012) Why subchondral bone in osteoarthritis? The importance of the cartilage bone interface in osteoarthritis. Osteoporos Int 23(Suppl 8):S841-S846

Martel-Pelletier J, Barr AJ, Cicuttini FM et al (2016) Osteoarthritis. Nat Rev Dis Primers 2:16072

Matthews GL, Hunter DJ (2011) Emerging drugs for osteoarthritis. Expert Opin Emerg Drugs 16(3):479-491

Mobasheri A (2013) The future of osteoarthritis therapeutics: targeted pharmacological therapy. Curr Rheumatol Rep 15(10):364

Mobasheri A, Batt M (2016) An update on the pathophysiology of osteoarthritis. Ann Phys Rehabil Med 59 (5-6):333-339

Mobasheri A, Csaki C, Clutterbuck AL, Rahmanzadeh M, Shakibaei M (2009) Mesenchymal stem cells in connective tissue engineering and regenerative medicine: applications in cartilage repair and osteoarthritis therapy. Histol Histopathol 24(3):347-366

Mobasheri A, Kalamegam G, Musumeci G, Batt ME (2014) Chondrocyte and mesenchymal stem cellbased therapies for cartilage repair in osteoarthritis and related orthopaedic conditions. Maturitas 78 (3):188-198

Mobasheri A, Matta C, Zákány R, Musumeci G (2015) Chondrosenescence: definition, hallmarks and potential role in the pathogenesis of osteoarthritis. Maturitas 80(3):237-244

Mobasheri A, Rayman MP, Gualillo O, Sellam J, van der Kraan P, Fearon U (2017) The role of metabolism in the pathogenesis of osteoarthritis. Nat Rev Rheumatol 13(5):302-311

Mobasheri A, van Spil WE, Budd E et al (2019) Molecular taxonomy of osteoarthritis for patient stratification, disease management and drug development: biochemical markers associated with emerging clinical phenotypes and molecular endotypes. Curr Opin Rheumatol 31(1):80-89

Murphy G (2017) Riding the metalloproteinase roller coaster. J Biol Chem 292(19):7708-7718

Omasa T, Onitsuka M, Kim W-D (2010) Cell engineering and cultivation of chinese hamster ovary (CHO) cells. Curr Pharm Biotechnol 11(3):233-240

Parmelee PA, Tighe CA, Dautovich ND (2015) Sleep disturbance in osteoarthritis: linkages with pain, disability, and depressive symptoms. Arthritis Care Res 67(3):358-365

Poulet B, Beier F (2016) Targeting oxidative stress to reduce osteoarthritis. Arthritis Res Ther 18(1):32

Rahmati M, Mobasheri A, Mozafari M (2016) Inflammatory mediators in osteoarthritis: a critical review of the state-of-the-art, current prospects, and future challenges. Bone 85:81-90

Richardson SM, Kalamegam G, Pushparaj PN et al (2016) Mesenchymal stem cells in regenerative medicine: focus on articular cartilage and intervertebral disc regeneration. Methods 99:69-80

Salminen A, Kauppinen A, Kaarniranta K (2012) Emerging role of NF- $\kappa \mathrm{B}$ signaling in the induction of senescence-associated secretory phenotype (SASP). Cell Signal 24(4):835-845

Scanzello CR, Goldring SR (2012) The role of synovitis in osteoarthritis pathogenesis. Bone 51(2):249-257

Schuhmacher A, Gassmann O, Hinder M (2016) Changing R\&D models in research-based pharmaceutical companies. J Transl Med 14(1):105

Scotece M, Mobasheri A (2015) Leptin in osteoarthritis: focus on articular cartilage and chondrocytes. Life Sci 140:75-78

Sellam J, Berenbaum F (2010) The role of synovitis in pathophysiology and clinical symptoms of osteoarthritis. Nat Rev Rheumatol 6(11):625-635

Sharma A, Kudesia P, Shi Q, Gandhi R (2016) Anxiety and depression in patients with osteoarthritis: impact and management challenges. Open Access Rheumatol 8:103-113

Siebuhr AS, Bay-Jensen AC, Jordan JM et al (2016) Inflammation (or synovitis)-driven osteoarthritis: an opportunity for personalizing prognosis and treatment? Scand J Rheumatol 45(2):87-98 
Stampella A, Monteagudo S, Lories R (2018) Wnt signaling as target for the treatment of osteoarthritis. Best Pract Res Clin Rheumatol 31(5):721-729

Sutton S, Clutterbuck A, Harris P et al (2009) The contribution of the synovium, synovial derived inflammatory cytokines and neuropeptides to the pathogenesis of osteoarthritis. Vet J 179(1):10-24

Tonge DP, Pearson MJ, Jones SW (2014) The hallmarks of osteoarthritis and the potential to develop personalised disease-modifying pharmacological therapeutics. Osteoarthr Cartil 22(5):609-621

van Spil WE, Kubassova O, Boesen M, Bay-Jensen A-C, Mobasheri A (2019) Osteoarthritis phenotypes and novel therapeutic targets. Biochem Pharmacol 65:41-48

Vink T, Oudshoorn-Dickmann M, Roza M, Reitsma J-J, de Jong RN (2014) A simple, robust and highly efficient transient expression system for producing antibodies. Methods 65(1):5-10
Yang CY, Chanalaris A, Troeberg L (2017) ADAMTS and ADAM metalloproteinases in osteoarthritis looking beyond the "usual suspects". Osteoarthr Cartil 25(7):1000-1009

Yu SP, Hunter DJ (2016) Intra-articular therapies for osteoarthritis. Expert Opin Pharmacother 17(15):1-15

Zhang W, Moskowitz RW, Nuki G et al (2008) OARSI recommendations for the management of hip and knee osteoarthritis, part II: OARSI evidence-based, expert consensus guidelines. Osteoarthr Cartil 16(2):137-162

Zhang W, Ouyang H, Dass CR, Xu J (2016) Current research on pharmacologic and regenerative therapies for osteoarthritis. Bone Res 4:15040

Zucchelli S, Patrucco L, Persichetti F, Gustincich S, Cotella D (2016) Engineering translation in mammalian cell factories to increase protein yield: the unexpected use of long non-coding SINEUP RNAs. Comput Struct Biotechnol J 14:404-410

Open Access This chapter is licensed under the terms of the Creative Commons Attribution 4.0 International License (http://creativecommons.org/licenses/by/4.0/), which permits use, sharing, adaptation, distribution and reproduction in any medium or format, as long as you give appropriate credit to the original author(s) and the source, provide a link to the Creative Commons license and indicate if changes were made.

The images or other third party material in this chapter are included in the chapter's Creative Commons license, unless indicated otherwise in a credit line to the material. If material is not included in the chapter's Creative Commons license and your intended use is not permitted by statutory regulation or exceeds the permitted use, you will need to obtain permission directly from the copyright holder. 